\title{
Trapping of the highly strained [5](2,4)quinolinophane system
}

\author{
Maurice J. van Eis, ${ }^{\text {a,* }}$ Martin Lutz, ${ }^{\mathrm{b}}$ Anthony L. Spek, ${ }^{\mathrm{b}}$ Willem H. de Wolf ${ }^{\mathrm{c}}$ \\ and Friedrich Bickelhaupt ${ }^{\mathrm{c}}$ \\ ${ }^{a}$ Novartis Institutes for BioMedical Research, Lichtstrasse 35, CH-4056 Basel, Switzerland \\ ${ }^{\mathrm{b}}$ Bijvoet Center for Biomolecular Research, Department of Crystal and Structural Chemistry, Utrecht University, \\ Padualaan 8, NL-3584 CH Utrecht, The Netherlands \\ 'Scheikundig Laboratorium, Vrije Universiteit, De Boelelaan 1083, NL-1081 HV Amsterdam, The Netherlands
}

Received 25 September 2006; revised 23 November 2006; accepted 24 November 2006

Available online 26 December 2006

\begin{abstract}
The highly strained [5](2,4)quinolinophane system can be generated as an intermediate (2b), which is extremely susceptible towards the attack of both nucleophilic and electrophilic species. Addition of water at the carbon bridgehead C2 occurs rapidly and is followed by rearrangements to give a strain free product 10. An unusual carbene addition at the $\mathrm{N} 1=\mathrm{C} 2$ bond of $\mathbf{2 b}$ is proposed to explain the formation of the strained 'anti-Bredt' type olefin 11.
\end{abstract}

(C) 2006 Elsevier Ltd. All rights reserved.

\section{Introduction}

During the last four decades remarkable progress has been made in the field of small strained cyclophanes. ${ }^{1}$ The efforts directed towards the synthesis of systems with ever increasing strain energies have recently culminated in the isolation of the highly strained [1.1]paracyclophane system. ${ }^{2}$ Most of the highly strained systems contain a benzene ring bridged in the meta or para position by an oligomethylene bridge. Examples of heteroaromatic cyclophanes are more rare. The most strained representatives of such systems were synthesized as early as 1969 when Parham et al. reported the synthesis of the [6]metaquinolinophane derivative 2a from 1a (Scheme 1). ${ }^{3}$
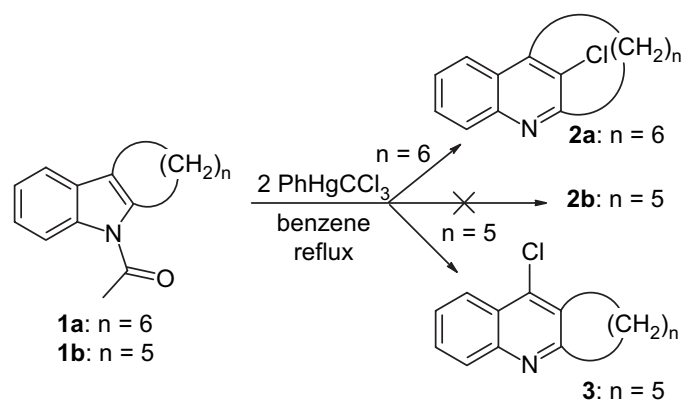

Scheme 1. Synthesis of $[6](2,4)$ quinolinophane $(\mathbf{2 a})$ by Parham et al. $^{3}$

\footnotetext{
Keywords: Cyclophanes; Strain; Small rings; Aromaticity.

* Corresponding author. Tel.: +41 61 3248293; fax: +41 61 3246735; e-mail: maurice.van_eis@novartis.com
}

The attempted formation of the corresponding [5] $(2,4)$ quinolinophane (2b) under similar reaction conditions led to the isolation of the unstrained ortho-isomer 3. The synthesis of the corresponding [6] $(2,4)$ pyridinophane was not reported until 1987 by Reese and Dhanak. ${ }^{4}$ The relative paucity of more strained examples of heterophanes may find its origin in the higher propensity of electron-poor heteroaromatics to undergo nucleophilic additions. Interesting in this respect is that in the $[n]$ metacyclophane series the smallest isolable member is [5]metacylophane, the synthesis of which was first reported in 1977 by Bickelhaupt et al..$^{5}$ Against this background, and in view of the absence of [5]metaheterophanes, we have adapted Parham's original synthetic route towards $\mathbf{2 b}$ in a way, which might allow the generation of the strained [5] $(2,4)$ quinolinophane system under mild reaction conditions, similar to those applied for the synthesis of [5]metacyclophane. Although $\mathbf{2 b}$ could not be isolated, we wish to present compelling evidence for its intermediate existence.

\section{Results and discussion}

Key to our approach is the protection of the indole derivative 4 with a protecting group, which can be cleaved under mild conditions (Scheme 2). For this purpose we have chosen the trimethylsilylethanesulfonyl (SES) group, which could be readily introduced using $\mathrm{NaH} / \mathrm{SES}-\mathrm{Cl}$ to afford $\mathbf{5}$. When 5 was subjected to a carbene addition under Makosza conditions ${ }^{6}\left(\mathrm{CHCl}_{3}, \mathrm{NaOH}\right.$, phase transfer catalyst $)$ the corresponding carbene adduct $\mathbf{6}$ was obtained in good yield. We envisioned that $\mathbf{6}$ could be deprotected with 
tetrabutylammonium fluoride (TBAF) under mild reaction conditions. Since attack of the fluoride ion leads to fragmentation of the SES group into trimethylsilyl fluoride, ethene and sulfur dioxide, this would initially lead to the indole $\mathrm{N}$-anion. It was hoped that cleavage of the SES group would be followed by immediate ring opening of the cyclopropyl ring and expulsion of a chloride anion. However, when the reaction was attempted, the sole product isolated after workup was the amine $\mathbf{7}$, which was found to be extremely labile in solution and which could only be characterized by ${ }^{1} \mathrm{H}$ NMR and direct inlet MS.
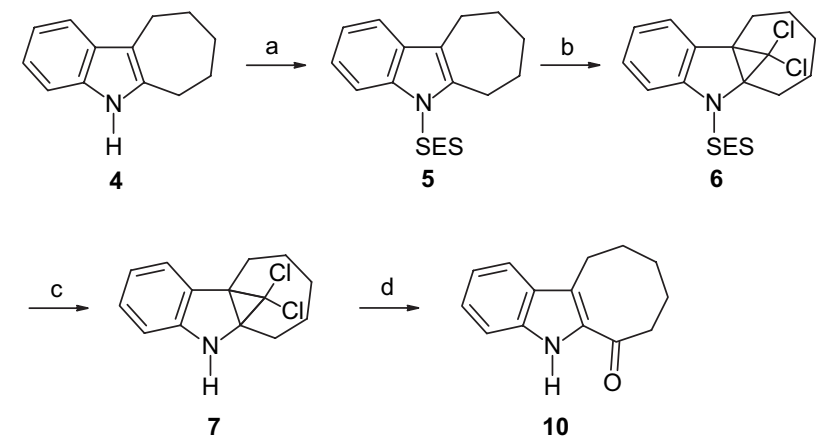

Scheme 2. Reagents and conditions: (a) NaH, SES-Cl, DMF, rt, 1 h, 39\%; (b) $\mathrm{NaOH}, \mathrm{CHCl}_{3}$, hexadecyltrimethylammonium bromide, rt, $18 \mathrm{~h}, 69 \%$; (c) TBAF $3 \mathrm{H}_{2} \mathrm{O}, \mathrm{Na}_{2} \mathrm{CO}_{3}$, THF, rt, $2 \mathrm{~h}, 75 \%$ and (d) $t$-BuOK, DMSO, $23 \%$.

Treatment of 7 with a strong base ( $t$-BuOK) in DMSO led to the formation of 10, which was isolated as a crystalline solid in $23 \%$ yield (Scheme 3 ). The structure of compound $\mathbf{1 0}$ could be incontrovertibly assigned based on its ${ }^{1} \mathrm{H}$ NMR and ${ }^{13} \mathrm{C}$ NMR spectra ${ }^{7}$ and was confirmed by a single crystal $\mathrm{X}$-ray structure determination (Fig. 1).
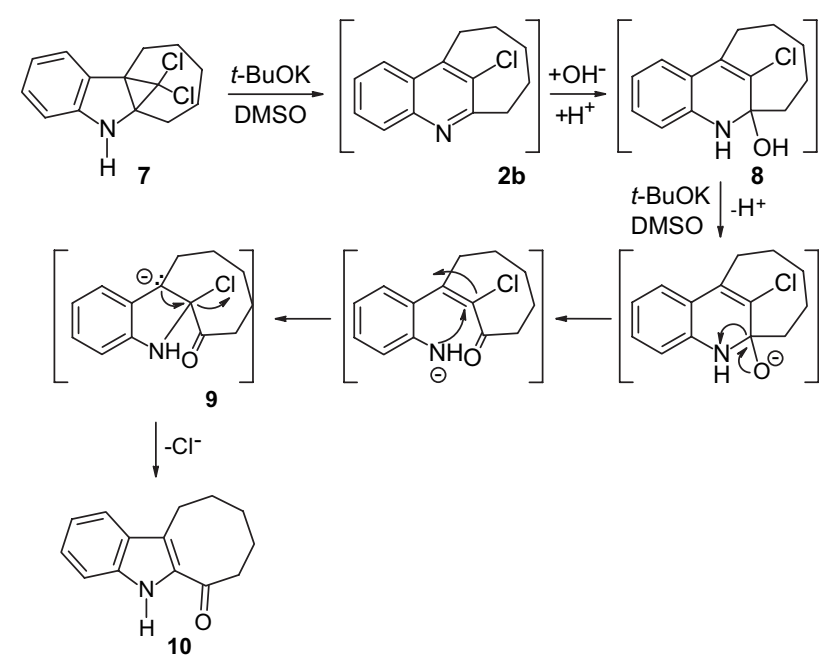

Scheme 3. Proposed mechanism for the formation of $\mathbf{1 0 .}$

A plausible mechanism for the base-promoted conversion of $\mathbf{7}$ to $\mathbf{1 0}$ is depicted in Scheme 3. It is assumed that $\mathbf{7}$ is rapidly converted into $\mathbf{8}$. The formation of $\mathbf{8}$ can proceed either via a water assisted disrotatory ring opening of the propellane 7 to give $\mathbf{8}$ directly, or via $\mathrm{HCl}$ elimination and intermediate formation of the [5](2,4)quinolinophane (2b), followed by subsequent nucleophilic attack of water or hydroxide ion at the bridgehead carbon atom $\mathrm{C} 2$.

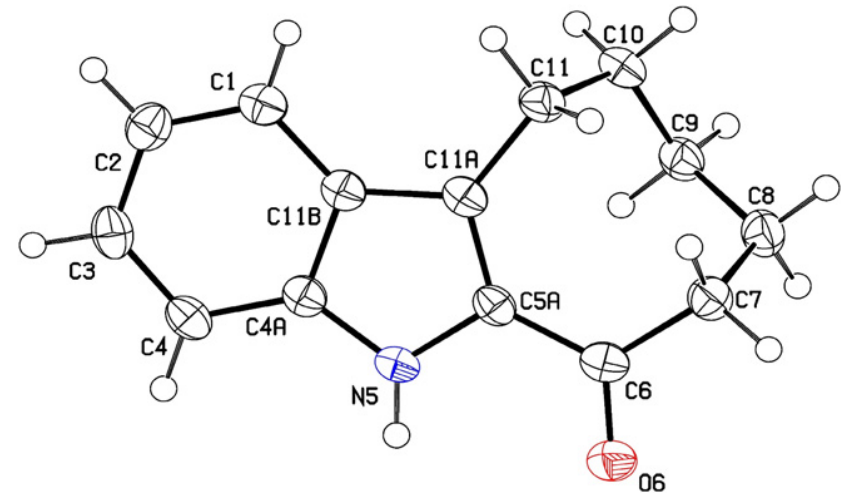

Figure 1. X-ray crystal structure of ketone 10. ${ }^{12}$ Displacement ellipsoids drawn at the $50 \%$ probability level. Selected bond lengths $(\AA)$ : $\mathrm{C}(4 \mathrm{a})-\mathrm{N}(5)$ 1.362(2), $\quad \mathrm{C}(4 \mathrm{a})-\mathrm{C}(11 \mathrm{~b}) \quad 1.415(3), \quad \mathrm{N}(5)-\mathrm{C}(5 \mathrm{a}) \quad 1.385(2), \quad \mathrm{C}(5 \mathrm{a})-\mathrm{C}(6)$

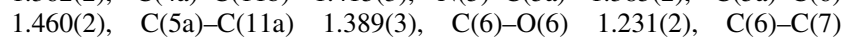
1.504(3), C(7)-C(8) 1.542(3), C(8)-C(9) 1.529(3), C(9)-C(10) 1.524(2), C(10)-C(11) 1.543(3), C(11)-C(11a) 1.499(3), C(11a)-C(11b) 1.415(3). Selected bond angles $\left({ }^{\circ}\right)$ : C (4a)-N(5)-C(5a) 109.0(1), C(4a)-C(11b)-C(11a) 107.6(2), N(5)-C(4a)-C(11b) 107.9(1), N(5)-C(5a)-C(6) 119.1(2), N(5)$\mathrm{C}(5 \mathrm{a})-\mathrm{C}(11 \mathrm{a})$ 109.6(1), $\mathrm{C}(5 \mathrm{a})-\mathrm{C}(6)-\mathrm{O}(6) \quad 120.7(2), \quad \mathrm{C}(5 \mathrm{a})-\mathrm{C}(6)-\mathrm{C}(7)$ 119.2(2), C(5a)-C(11a)-C(11) 128.7(1), C(5a)-C(11a)-C(11b) 105.9(2), $\mathrm{O}(6)-\mathrm{C}(6)-\mathrm{C}(7) \quad 120.1(1), \quad \mathrm{C}(6)-\mathrm{C}(7)-\mathrm{C}(8) \quad 113.2(2), \quad \mathrm{C}(7)-\mathrm{C}(8)-\mathrm{C}(9)$ 116.9(2), C(8)-C(9)-C(10) 117.1(2), C(9)-C(10)-C(11) 116.8(2), C(10)$\mathrm{C}(11)-\mathrm{C}(11 \mathrm{~A}) 114.4(2), \mathrm{C}(11)-\mathrm{C}(11 \mathrm{a})-\mathrm{C}(11 \mathrm{~b})$ 125.4(2). Selected torsion angles $\left({ }^{\circ}\right)$ : $\mathrm{N}(5)-\mathrm{C}(5 \mathrm{a})-\mathrm{C}(6)-\mathrm{O}(6) 0.8(3)$.

Interestingly, products similar to $\mathbf{1 0}$ and $\mathbf{8}$ have been observed in the context of an attempted synthesis of the corresponding $[5](1,3)$ naphthalenophane ${ }^{8}$ and in a previous attempt to generate the [5](2,4)quinolinophane system, respectively. ${ }^{9}$ The next reaction steps most probably involve deprotonation of the $\mathrm{OH}$-group followed by cleavage of the $\mathrm{C}-\mathrm{N}$ bond. Subsequent intramolecular attack of the resulting aniline anion at the $\beta$-carbon atom of the enone function is counteracted by strain in the resulting four-membered ring. Alternative attack at the $\alpha$-carbon leading to the benzylic anion 9 seems a priori less likely because of the $\mathrm{p} K_{\mathrm{a}}$-values of the aniline anion and benzylic anion, but it is facilitated by relief of the strain of the trans-double bond. Subsequent expulsion of a chloride ion leads to the formation of $\mathbf{1 0}$.

An alternative method for the formation of trans-cyclooctene derivatives, which ultimately led to the successful synthesis and isolation of [5](1,3)naphthalenophane, has been the silver(I) perchlorate promoted ring expansion of halogenated carbene adducts. ${ }^{10}$ However, attempted formation of $\mathbf{2 b}$ from $\mathbf{7}$ with silver(I) perchlorate and 2,6-lutidine in anhydrous THF did not give the desired product (Scheme 4). Instead, two main products were isolated in low yields $(<5 \%)$ in an approximate $4: 1$ ratio. The first product was identified as the starting indole $\mathbf{4}$, whereas structure $\mathbf{1 1}$ was tentatively assigned to the second product, based on its ${ }^{1} \mathrm{H}$ NMR and MS spectra. These observations have several implications: part of the starting material 7 must undergo a ring opening and simultaneous hydrogen chloride elimination to give $\mathbf{2 b}$. The presence of the 'free' indole $\mathbf{4}$ signals that another part of the propellane structure of $\mathbf{7}$ might undergo a retro-carbene addition. To our knowledge, simple retro-carbene additions are unknown, unless the second product is a highly stabilized aromatic compound such as a derivative of benzene; however, silver ion catalyzed opening of a three-membered ring has been reported. ${ }^{11}$ Thus the generated dichlorocarbene, or possibly its $\mathrm{Ag}^{+}$ 


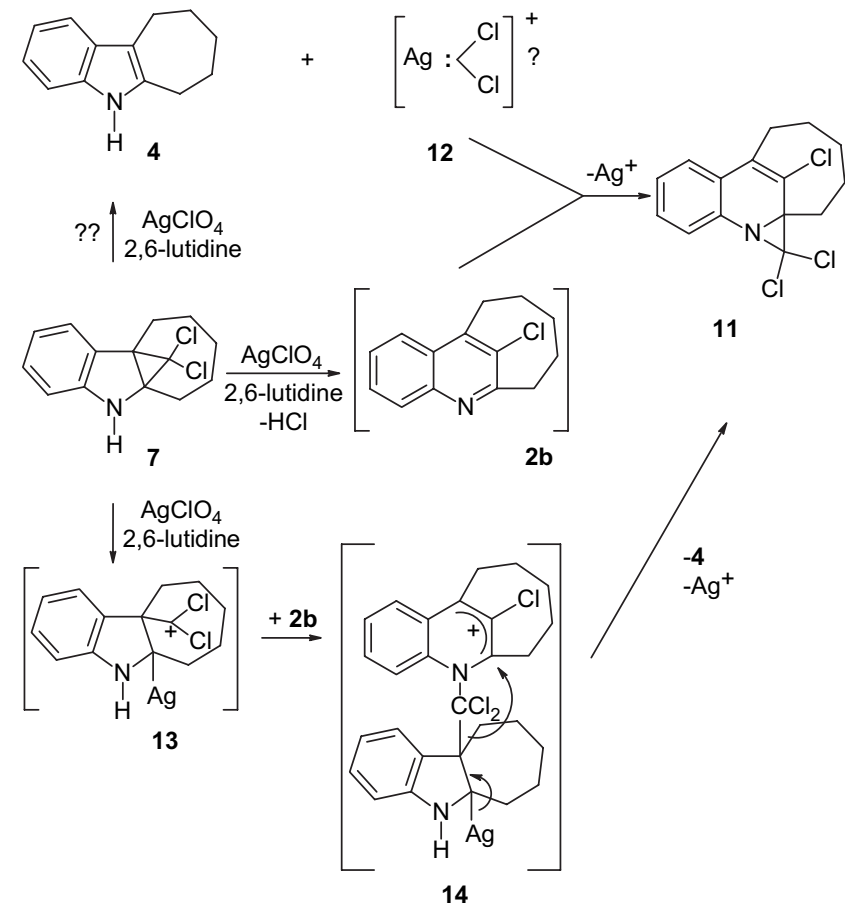

Scheme 4. Proposed mechanism for the formation of $\mathbf{1 1}$.

adduct $\mathbf{1 2}$, then recombines with the quinolinophane $\mathbf{2 b}$ to give the carbene adduct 11 (Scheme 4). A conceivable alternative pathway might be opening of the three-membered ring of 7 by $\mathrm{Ag}^{+}$under formation of $\mathbf{1 3}$, which attacks $\mathbf{2 b}$ to give intermediate 14; the latter could cleave off 4 and $\mathrm{Ag}^{+}$under formation of $\mathbf{1 1}$ as indicated.

The small amounts of $\mathbf{1 1}$ generated in this reaction did not allow an unambiguous assignment of its structure. More material was obtained in an unexpected way when we attempted to re-synthesize the ortho-isomer $\mathbf{3}$ as a reference compound using the method reported by Parham for $\mathbf{1 b} .^{3 b}$ However, in our hands the reaction of $\mathbf{4}$ with phenyltrichloromethylmercury in refluxing benzene afforded a small amount of $3(2 \%)$ only, together with a product, which had all the spectroscopic characteristics identical to those of $\mathbf{1 1}(11 \%)$. Based on its ${ }^{1} \mathrm{H} \mathrm{NMR},{ }^{13} \mathrm{C}$ NMR and HRMS spectra, the structure of $\mathbf{1 1}$ could be unambiguously assigned. Crystals were grown from a pentane solution and an X-ray crystal structure was obtained (Fig. 2), which incontrovertibly proved the assigned structure. The yield of 11 was further improved to $21 \%$ by reacting 4 under phase transfer conditions with $\mathrm{CHCl}_{3} / \mathrm{NaOH}$. Using these reaction conditions a large excess of the dichlorocarbene is generated, which allows rapid trapping of the intermediate $\mathbf{2 b}$ (Scheme 5).

This formation of $\mathbf{1 1}$ is interesting for several reasons: in the first place, it does lend support to our rationalization of the formation of $\mathbf{1 1}$ as depicted in Scheme 4. It implies that $\mathbf{2 b}$ might be formed as an intermediate via the addition of a dichlorocarbene to $\mathbf{4}$, followed by formal hydrogen chloride elimination and ring opening. The large excess of sodium hydroxide in the latter procedure rapidly neutralizes any formed acid and thus may prevent an acid catalyzed rearrangement of $\mathbf{2 b}$ to its ortho-isomer $\mathbf{3}$. Secondly, the formation of $\mathbf{1 1}$ as the sole identifiable reaction product implies

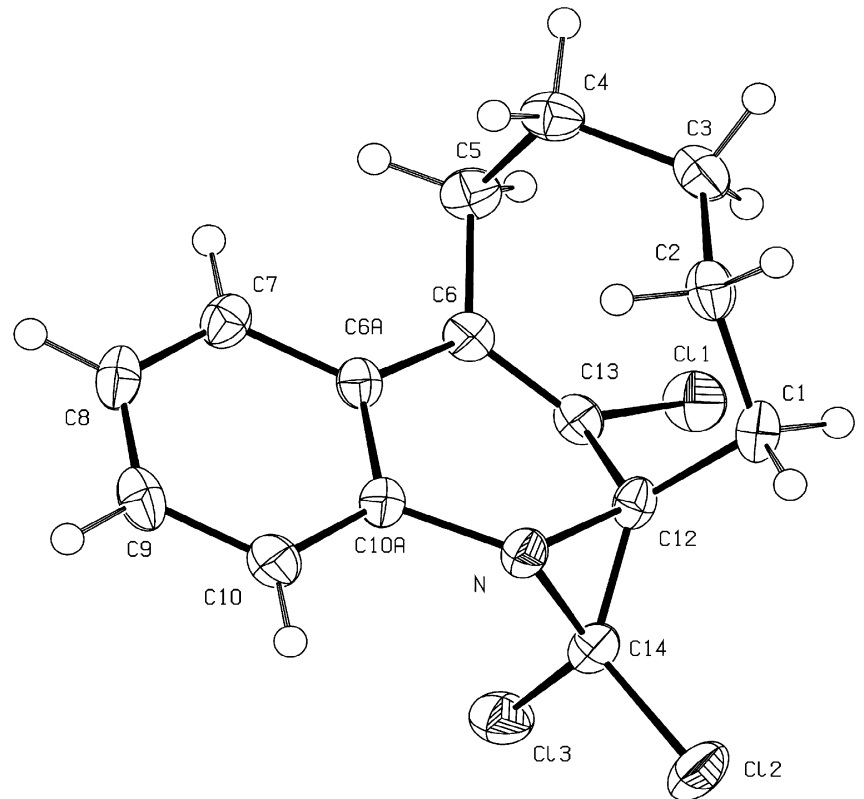

Figure 2. X-ray crystal structure of adduct $11 .{ }^{12}$ Displacement ellipsoids drawn at the $50 \%$ probability level. Selected bond lengths $(\AA)$ : $\mathrm{C}(1)-\mathrm{C}(2)$ 1.541(2), C(1)-C(12) 1.515(2), C(2)-C(3) 1.556(2), C(3)-C(4) 1.546(2), $\mathrm{C}(4)-\mathrm{C}(5)$ 1.546(2), C(5)-C(6) 1.491(2), C(6)-C(13) 1.335(2), C(10A)-N 1.422(2), $\quad \mathrm{C}(12)-\mathrm{C}(13) \quad 1.478(2), \quad \mathrm{C}(12)-\mathrm{N} \quad 1.473(2), \quad \mathrm{C}(12)-\mathrm{C}(14)$ 1.488(2), C(14)-N 1.424(2). Selected bond angles $\left(^{\circ}\right)$ : $\mathrm{C}(1)-\mathrm{C}(2)-\mathrm{C}(3)$ 119.0(1), C(1)-C(12)-C(13) 110.4(1), C(1)-C(12)-C(14) 128.4(1), C(1)$\mathrm{C}(12)-\mathrm{N} 113.7(1), \mathrm{C}(2)-\mathrm{C}(1)-\mathrm{C}(12) 110.3(1), \mathrm{C}(2)-\mathrm{C}(3)-\mathrm{C}(4) 118.6(1)$, $\mathrm{C}(3)-\mathrm{C}(4)-\mathrm{C}(5)$ 115.9(1), C(4)-C(5)-C(6) 104.4(1), C(5)-C(6)-C(6A) $120.8(1), \quad \mathrm{C}(5)-\mathrm{C}(6)-\mathrm{C}(13) \quad 121.0(1), \quad \mathrm{C}(6)-\mathrm{C}(13)-\mathrm{C}(12) \quad 118.9(1)$, $\mathrm{C}(12)-\mathrm{C}(14)-\mathrm{N} \quad 60.8(1), \quad \mathrm{C}(12)-\mathrm{N}-\mathrm{C}(10 \mathrm{~A}) \quad 119.4(1), \quad \mathrm{C}(12)-\mathrm{N}-\mathrm{C}(14)$ 61.8(1), C(13)-C(12)-N 114.4(1), C(13)-C(12)-C(14) 119.3(1), C(14)$\mathrm{N}-\mathrm{C}(10 \mathrm{~A})$ 128.0(1), N-C(12)-C(14) 57.5(1). Selected torsion angles $\left(^{\circ}\right)$ : $\mathrm{C}(5)-\mathrm{C}(6)-\mathrm{C}(13)-\mathrm{C}(12) \quad 133.3(1), \quad \mathrm{C}(5)-\mathrm{C}(6)-\mathrm{C}(13)-\mathrm{Cl}(1)-26.7(1)$, $\mathrm{C}(6 \mathrm{~A})-\mathrm{C}(6)-\mathrm{C}(13)-\mathrm{C}(12)-34.5, \mathrm{C}(6 \mathrm{~A})-\mathrm{C}(6)-\mathrm{C}(13)-\mathrm{Cl}(1)$ 165.5(1).

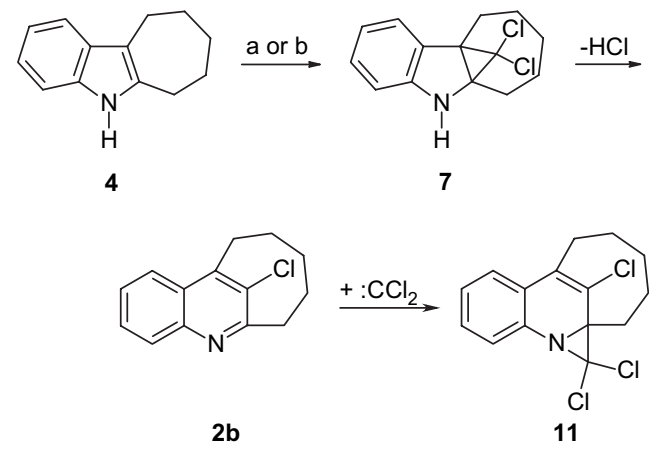

Scheme 5. Reagents and conditions: (a) $\mathrm{PhHgCCl}_{3}$, benzene, reflux, $18 \mathrm{~h}$, $11 \%$; (b) $\mathrm{NaOH}, \mathrm{CHCl}_{3}$, hexadecyltrimethylammonium bromide, rt, $18 \mathrm{~h}, 21 \%$.

that $\mathbf{2 b}$ rapidly and selectively reacts with an electrophilic species, such as dichlorocarbene, $\mathbf{1 2}$, or $\mathbf{1 3}$, at the $\mathrm{C}=\mathrm{N}$ double bond. A literature survey reveals that addition of dichlorocarbene to benzene or pyridine rings is extremely rare. The addition of dichlorocarbene to the strained [5]metacyclophane system has been reported, but in this case addition takes place across the strained anti-Bredt type double bond, and is followed by several further transformations. ${ }^{13}$ The only example of the formation of an aziridine ring by the addition of a carbene to a six-membered heterocyclic system involves the addition of a sulfonyl carbene to the 
benzo $[h][1,6]$ naphthyridine system. ${ }^{14}$ One would have expected the carbene addition to take place across the strained anti-Bredt type double bond of $\mathbf{2 b}$ in analogy to [5]metacyclophane. However, the observed regioselectivity can be explained by FMO theory. The addition of a dichlorocarbene to a double bond is assumed to involve a so-called one step, two-phase mechanism in which the first phase involves the interaction of the empty p-orbital of the carbene with the HOMO of the double bond or conjugated system. An analysis of the HOMO energy levels and orbital coefficients of $\mathbf{2 b}$ and the reference compound 3-chloro-2,4-dimethylquinoline (15) ${ }^{15,16}$ shows that the HOMO of $\mathbf{1 5}$ is mainly centred around the $\mathrm{C} 3-\mathrm{C} 4$ bond and possesses an energy level of $-6.24 \mathrm{eV}$ (Fig. 3). Therefore, carbene additions should preferentially take place at $\mathrm{C} 3-\mathrm{C} 4$. As a consequence of the strain energy introduced by the short pentamethylene spacer, the HOMO energy of $\mathbf{2 b}$ is substantially elevated $E(\mathrm{HOMO})=-5.90 \mathrm{eV}$; most importantly, its HOMO bears larger orbital coefficients at $\mathrm{N} 1$ and $\mathrm{C} 2$ than at $\mathrm{C} 3$ and $\mathrm{C} 4$.

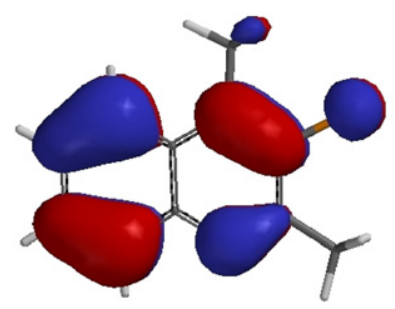

15

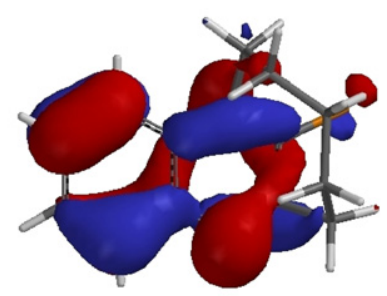

$2 b$
Figure 3. HOMO coefficients of $\mathbf{1 5}$ and $\mathbf{2 b}$.

Finally, the structure of $\mathbf{1 1}$ itself contains several interesting features of which the strained anti-Bredt type double bond is the most eye-catching. Upon addition of a carbene to the $\mathrm{N} 1=\mathrm{C} 2$ double bond of $\mathbf{2 b}$, the strain energy is considerably reduced by $76 \mathrm{~kJ} / \mathrm{mol}$. However, 11 still contains a residual strain energy (SE) of $110 \mathrm{~kJ} / \mathrm{mol}$ as assessed by a homodesmotic reaction scheme depicted in Scheme 6. ${ }^{15,16}$
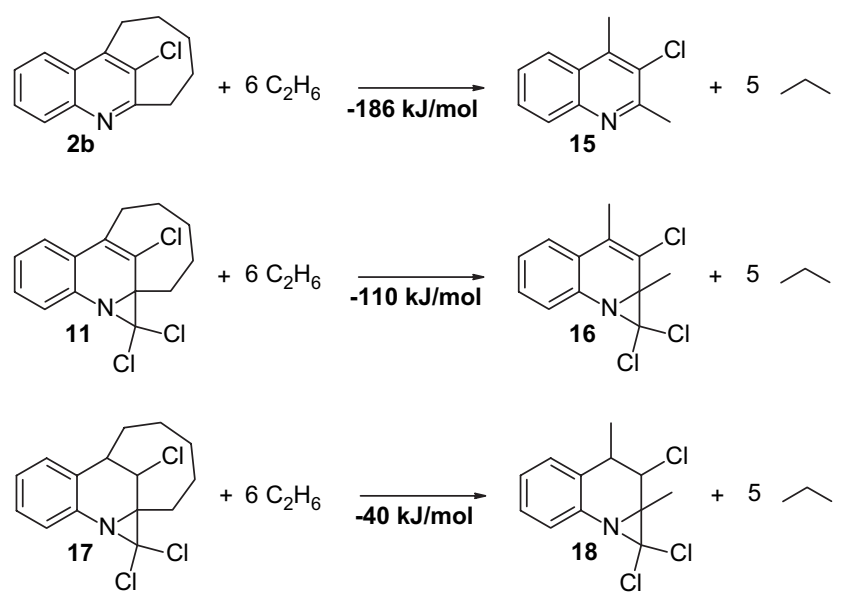

Scheme 6. Homodesmotic reaction schemes.

The strain energy is largely caused by twisting around the double bond as indicated by the large torsion angles between the cis-substituents of the olefin: $\phi_{1}(\mathrm{C}(6 \mathrm{~A})-\mathrm{C}(6)-\mathrm{C}(13)-$ $\mathrm{C}(12))=-34.5^{\circ}$ and $\phi_{2}(\mathrm{C}(5)-\mathrm{C}(6)-\mathrm{C}(13)-\mathrm{Cl}(1))=-26.7^{\circ}$. Pyramidalization occurs to a lesser extent as indicated by pyramidalization angles $\chi^{17}$ of the two olefinic carbon atoms: $\chi_{1}(\mathrm{C}(5)-\mathrm{C}(6)-\mathrm{C}(13)-\mathrm{C}(6 \mathrm{~A}))=12.2^{\circ}$ and $\chi_{2}(\mathrm{C}(12)$ $\mathrm{C}(13)-\mathrm{C}(6)-\mathrm{Cl}(1))=19.9^{\circ}$.

Using homodesmotic reaction schemes, the olefinic strain energy (OS), ${ }^{18}$ which is defined as the difference in SE between the lowest energy conformer of the olefin minus the $\mathrm{SE}$ of the lowest energy of the corresponding hydrogenated compound, was evaluated to amount to $70 \mathrm{~kJ} / \mathrm{mol}(16.8 \mathrm{kcal} /$ mol). To our knowledge $\mathbf{1 1}$ thus represents one of the most strained, yet isolable olefins. ${ }^{19}$ Although we were not able thus far to isolate $\mathbf{2 b}$, its thermodynamic stability should be sufficient to allow its isolation based on an evaluation of its strain energy using a similar homodesmotic reaction scheme (Scheme 6). The SE energy of $\mathbf{2 b}$ was assessed to be $186.3 \mathrm{~kJ} / \mathrm{mol}$, which is approximately $10 \mathrm{~kJ} / \mathrm{mol}$ lower than for the corresponding 2-chloro[5](1,3)naphthalenophane, which has been successfully isolated. ${ }^{10}$

\section{Conclusion}

In summary, we have demonstrated that the $[5](2,4)$ quinolinophane system has been generated as an intermediate (2b), but it is susceptible to the attack by both electrophilic and nucleophilic species at the $\mathrm{N} 1=\mathrm{C} 2$ bond, which so far has prevented its isolation.

\section{Experimental}

\subsection{General}

${ }^{1} \mathrm{H}$ and ${ }^{13} \mathrm{C}$ NMR spectra were recorded on a Bruker MSL 400 spectrometer at 400.13 and $100.32 \mathrm{MHz}$, respectively. ${ }^{1} \mathrm{H}$ NMR spectra were referenced to $\mathrm{CHCl}_{3}(\delta 7.27 \mathrm{ppm})$ and ${ }^{13} \mathrm{C}$ NMR spectra to $\mathrm{CDCl}_{3}(\delta 77.0 \mathrm{ppm})$. High-resolution mass spectrometry (HRMS) was performed on a Finnigan MAT-90 mass spectrometer operating at an ionization potential of $70 \mathrm{eV}$. Melting points were measured on samples in unsealed capillary tubes and are uncorrected.

4.1.1. 5,6,7,8,9,10-Hexahydrocyclohepta[b]indole (4). Phenylhydrazine $(10.82 \mathrm{~g}, 100 \mathrm{mmol})$ was added during a period of $30 \mathrm{~min}$ to a refluxing solution of cycloheptanone $(11.22 \mathrm{~g}, 100 \mathrm{mmol})$ in acetic acid $(160 \mathrm{~mL})$. The resulting brown reaction mixture was stirred at reflux for an additional $30 \mathrm{~min}$ and subsequently allowed to cool down to room temperature. The crystalline product formed, which was collected, was washed once with cold $50 \%$ aqueous methanol and several times with water to yield $\mathbf{4}$ as pale yellow platelets. Yield: $13.8 \mathrm{~g}(74 \%, 74 \mathrm{mmol}) . \mathrm{Mp} 138-142{ }^{\circ} \mathrm{C} ;{ }^{1} \mathrm{H}$ NMR $\left(400.13 \mathrm{MHz}, \mathrm{CDCl}_{3}, 298 \mathrm{~K}\right.$ ): $\delta 7.75-7.68$ (br s, $1 \mathrm{H}), 7.68-7.64(\mathrm{~m}, 1 \mathrm{H}), 7.41-7.37(\mathrm{~m}, 1 \mathrm{H}), 7.29-7.25(\mathrm{~m}$, 2H), 3.02-2.93 (m, 4H), 2.11-2.04 (m, 2H), 1.98-1.91 (m, $4 \mathrm{H}) ;{ }^{13} \mathrm{C}$ NMR $\left(100.64 \mathrm{MHz}, \mathrm{CDCl}_{3}, 298 \mathrm{~K}\right): \delta 137.7$, $134.5,129.5,120.9,119.3,117.9,113.9,110.5,32.1,29.8$, 29.0, 27.8, 24.9; HRMS: $[\mathrm{M}]^{+}$, found 185.1204. $\mathrm{C}_{13} \mathrm{H}_{15} \mathrm{~N}$ requires 185.1205 .

4.1.2. 5-(2-Trimethylsilanylethanesulfonyl)-5,6,7,8,9,10hexahydrocyclohepta[b]indole (5). To a suspension of $\mathrm{NaH}(300 \mathrm{mg}, 12.5 \mathrm{mmol})$ in DMF $(25 \mathrm{~mL})$ was slowly 
added a solution of $4(2.04 \mathrm{~g}, 11.0 \mathrm{mmol})$ in $\mathrm{DMF}(10 \mathrm{~mL})$ at $0{ }^{\circ} \mathrm{C}$ under an argon atmosphere. After stirring for $30 \mathrm{~min}$ at $0{ }^{\circ} \mathrm{C}$, a solution of 2-trimethylsilanylethanesulfonyl chloride $(2.81 \mathrm{~g}, 14.0 \mathrm{mmol})$ in DMF $(15 \mathrm{~mL})$ was slowly added at $0{ }^{\circ} \mathrm{C}$. The reaction mixture was stirred for $1 \mathrm{~h}$ at $0{ }^{\circ} \mathrm{C}$, and subsequently allowed to warm up to room temperature over $1 \mathrm{~h}$. A saturated aqueous ammonium chloride solution was added $(50 \mathrm{~mL})$ and the mixture was extracted with ethyl acetate $(3 \times 75 \mathrm{~mL})$. The combined organic layers were washed with water $(100 \mathrm{~mL})$, brine $(100 \mathrm{~mL})$ and dried over anhydrous sodium sulfate. Removal of the solvents under reduced pressure afforded a black oil, which was purified by flash column chromatography on silica gel using cyclohexane/ethyl acetate $97: 3$ as an eluent to afford $\mathbf{5}$ as a yellow oil. Yield: $1.49 \mathrm{~g}(39 \%, 4.3 \mathrm{mmol}) . R_{f}\left(\mathrm{SiO}_{2} /\right.$ cyclohexane/ethyl acetate 95:5) $=0.44 ;{ }^{1} \mathrm{H}$ NMR $(400.13 \mathrm{MHz}$, $\left.\mathrm{CDCl}_{3}, 298 \mathrm{~K}\right): \delta$ 8.05-8.01 (m, 1H), 7.48-7.44 (m, 1H), 7.29-7.23 (m, 2H), 3.27-3.22 (m, 2H), 3.13-3.07 (m, 2H), 2.81-2.77 (m, 2H), 1.93-1.87 (m, 2H), 1.84-1.74 (m, $4 \mathrm{H}), \quad 0.87-0.81(\mathrm{~m}, 2 \mathrm{H}),-0.05(\mathrm{~s}, 9 \mathrm{H}) ;{ }^{13} \mathrm{C}$ NMR $\left(100.64 \mathrm{MHz}, \mathrm{CDCl}_{3}, 298 \mathrm{~K}\right): \delta 139.8,136.6,130.6$, $124.0,123.3,122.7,118.2,114.9,51.4,31.4,27.2,27.1$, 26.9, 23.9, 10.1, -1.8 (3C, $\left.\mathrm{SiMe}_{3}\right)$; MS (70 eV) m/z 349 $\left(\mathrm{M}^{+}\left(\mathrm{C}_{18} \mathrm{H}_{17} \mathrm{NO}_{2} \mathrm{SSi}\right), 15.9\right), 285$ (11.6), 257 (17.1), 184 (16.2), 73 (100); HRMS: [M] $]^{+}$, found 349.1532 . $\mathrm{C}_{18} \mathrm{H}_{27} \mathrm{NO}_{2} \mathrm{SSi}$ requires 349.1532 .

\subsubsection{5,15-Dichloro-8-(2-trimethylsilanylethanesul-} fonyl)-8-azatetracyclo[7.5.1.0 $\left.{ }^{1,9} .0^{2,7}\right]$ pentadeca-2(3),4,6triene (6). To a solution of $5(979 \mathrm{mg}, 2.80 \mathrm{mmol})$, hexadecyltrimethylammonium bromide $(10.2 \mathrm{mg}, 0.028 \mathrm{mmol})$ and one drop of ethanol in $\mathrm{CHCl}_{3}(6.02 \mathrm{~g}, 50.4 \mathrm{mmol})$ $50 \%$ aqueous $\mathrm{NaOH}(1.68 \mathrm{~g}, 42.0 \mathrm{mmol})$ was added under cooling with ice. The resulting brown two-phase system was vigorously stirred for $18 \mathrm{~h}$ at room temperature, poured into ice water and extracted with $\mathrm{CH}_{2} \mathrm{Cl}_{2}(3 \times)$. The combined organic layers were washed with water $(2 \times)$, brine $(1 \times)$, dried over $\mathrm{Na}_{2} \mathrm{SO}_{4}$ and concentrated at reduced pressure. The crude product was purified by flash column chromatography (silica gel, cyclohexane/EtOAc 98:2) to afford 6 as a pale yellow solid. Yield: $839 \mathrm{mg}(69 \%, 1.94 \mathrm{mmol}) . R_{f}$ $\left(\mathrm{SiO}_{2} /\right.$ cyclohexane/EtOAc 98:2)=0.27. Mp $138{ }^{\circ} \mathrm{C} ;{ }^{1} \mathrm{H}$ NMR (400.13 MHz, $\left.\mathrm{CDCl}_{3}, 298 \mathrm{~K}\right): \delta 7.23-7.17(\mathrm{~m}, 3 \mathrm{H})$, 7.01-6.96 (m, 1H), 3.19-3.07 (m, 2H), $2.87(\mathrm{dd}$, $\left.J_{\mathrm{AB}}=-15.7 \mathrm{~Hz}, 5.9 \mathrm{~Hz}, 1 \mathrm{H}\right), 2.60\left(\mathrm{dd}, J_{\mathrm{AB}}=-15.6 \mathrm{~Hz}\right.$, $6.6 \mathrm{~Hz}, 1 \mathrm{H}), 191-1.73(\mathrm{~m}, 5 \mathrm{H}), 1.39-1.28(\mathrm{~m}, 1 \mathrm{H}), 1.23-$ $1.03(\mathrm{~m}, 4 \mathrm{H}) ;{ }^{13} \mathrm{C} \mathrm{NMR}\left(100.64 \mathrm{MHz}, \mathrm{CDCl}_{3}, 298 \mathrm{~K}\right)$ : $\delta 146.2,130.5,129.3,124.6,123.1,113.9,70.7,63.7$, 53.3, 47.6, 31.7, 28.8, 28.4, 27.3, 26.6, 10.3, -1.7 (3C); HRMS: $[\mathrm{M}]^{+}$, found 431.0908. $\mathrm{C}_{19} \mathrm{H}_{27} \mathrm{Cl}_{2} \mathrm{NO}_{2} \mathrm{SSi}$ requires 431.0909 .

4.1.4. 15,15-Dichloro-8-azatetracyclo[7.5.1.0 $\left.{ }^{1,9} \cdot 0^{2,7}\right]$ pentadeca-2(3),4,6-triene (7). To a solution of $6(432 \mathrm{mg}$, $1.0 \mathrm{mmol})$ in dry THF $(25 \mathrm{~mL})$ was added TBAF $3 \mathrm{H}_{2} \mathrm{O}$ (1.29 g, $3.5 \mathrm{mmol})$ and $\mathrm{Na}_{2} \mathrm{CO}_{3}(198 \mathrm{mg}, 2.0 \mathrm{mmol})$. After stirring for $2 \mathrm{~h}$ at room temperature, the reaction mixture was partitioned between brine $(50 \mathrm{~mL})$ and diethyl ether $(50 \mathrm{~mL})$. The layers were separated and the aqueous layer was extracted with diethyl ether. The combined organic layers were washed with brine, dried $\left(\mathrm{Na}_{2} \mathrm{SO}_{4}\right)$ and concentrated under reduced pressure to afford 7 as a yellow oil. Yield: $200 \mathrm{mg}(75 \%, 0.75 \mathrm{mmol}) . R_{f}\left(\mathrm{SiO}_{2} /\right.$ cyclohexane/
EtOAc $90: 10)=0.20 ;{ }^{1} \mathrm{H} \quad \mathrm{NMR} \quad\left(400.13 \mathrm{MHz}, \mathrm{CDCl}_{3}\right.$, $298 \mathrm{~K}): \delta 7.18(\mathrm{~d}, J=7.8 \mathrm{~Hz}, 1 \mathrm{H}), 7.03(\mathrm{t}, J=7.8 \mathrm{~Hz}, 1 \mathrm{H})$, $6.65(\mathrm{t}, J=7.8 \mathrm{~Hz}, 1 \mathrm{H}), 6.48(\mathrm{~d}, J=7.8 \mathrm{~Hz}, 1 \mathrm{H}), 4.51(\mathrm{br}$ $\mathrm{s}, 1 \mathrm{H}), 3.20-3.11(\mathrm{~m}, 1 \mathrm{H}), 2.87-2.80(\mathrm{~m}, 1 \mathrm{H}), 2.59-2.48$ (m, 1H), 2.09-1.99 (m, 1H), 1.78-1.39 (m, 8H), 1.27-1.12 $(\mathrm{m}, 2 \mathrm{H})$; MS $(70 \mathrm{eV}) \mathrm{m} / z 267\left(\mathrm{M}^{+}\left(\mathrm{C}_{14} \mathrm{H}_{15}{ }^{35} \mathrm{Cl}_{2} \mathrm{~N}\right), 19\right)$, 232 (100).

4.1.5. 5,7,8,9,10,11-Hexahydrocycloocta[b]indol-6-one (10). To a solution of 7 (199 $\mathrm{mg}, 0.75 \mathrm{mmol})$ in dry DMSO $(10 \mathrm{~mL})$ was added during a period of $1 \mathrm{~h} t$-BuOK (92 $\mathrm{mg}, 0.82 \mathrm{mmol})$. After another $1 \mathrm{~h}$ of stirring, the reaction mixture was partitioned between ice water $(200 \mathrm{~mL})$ and diethyl ether $(75 \mathrm{~mL})$. The layers were separated and the aqueous layer was extracted four times with diethyl ether. The combined organic layers were washed with water $(3 \times)$, dried $\left(\mathrm{MgSO}_{4}\right)$ and concentrated under reduced pressure to afford a yellow oil. The crude product was purified by flash column chromatography $\left(\mathrm{Al}_{2} \mathrm{O}_{3} / \mathrm{CH}_{2} \mathrm{Cl}_{2}\right)$ to afford 10 as colorless crystals. Yield: $36 \mathrm{mg}(23 \%, 0.17 \mathrm{mmol})$; ${ }^{1} \mathrm{H}$ NMR (400.13 MHz, $\mathrm{CDCl}_{3}, 298 \mathrm{~K}$ ): $\delta 8.95$ (br s, $\left.1 \mathrm{H}\right)$, $7.72(\mathrm{~d}, J=6.7 \mathrm{~Hz}, 1 \mathrm{H}), 7.41-7.08(\mathrm{~m}, 3 \mathrm{H}), 3.32(\mathrm{t}$, $J=7.0 \mathrm{~Hz}, 2 \mathrm{H}), 3.03(\mathrm{t}, J=7.3 \mathrm{~Hz}, 2 \mathrm{H}), 1.92-1.68(\mathrm{~m}, 4 \mathrm{H})$, 1.54-1.36 (m, 2H); ${ }^{13} \mathrm{C}$ NMR $\left(100.64 \mathrm{MHz}, \mathrm{CDCl}_{3}\right.$, $298 \mathrm{~K}): \delta 193.7,136.2,135.0,127.8,126.2,121.7,120.8$, 119.9, 111.9, 40.4, 25.2, 23.6, 23.1, 22.5; HRMS: $[\mathrm{M}]^{+}$, found 213.1157. $\mathrm{C}_{14} \mathrm{H}_{15} \mathrm{NO}$ requires 213.1154.

4.1.6. 9,9,16-Trichloro-8-azatetracyclo $\left[8.5 \cdot 1.0^{2,7} \cdot 0^{8,10}\right]$ hexadeca-1(16),2,4,6-tetraene (11) and 10-chloro2,3,4,5-tetrahydro- $H$-cyclohepta[1,2,-b]quinoline (3). To a solution of $4(925 \mathrm{mg}, 5.0 \mathrm{mmol})$ in anhydrous benzene $(50 \mathrm{~mL})$ was added $\mathrm{PhHgCCl}_{3}(4.35 \mathrm{~g}, 11.0 \mathrm{mmol})$. The reaction mixture was heated under reflux for $24 \mathrm{~h}$. After removal of the solvent at reduced pressure the residue was subjected to flash column chromatography using pentane as an eluent to afford $\mathbf{1 1}$ and $\mathbf{3}$ as white solids. 11: yield: $175 \mathrm{mg}(11 \%, 0.56 \mathrm{mmol}) ; R_{f}\left(\mathrm{SiO}_{2} /\right.$ pentane $)=0.50 . \mathrm{Mp}$ $94{ }^{\circ} \mathrm{C} ;{ }^{1} \mathrm{H}$ NMR $\left(400.13 \mathrm{MHz}, \mathrm{CDCl}_{3}, 298 \mathrm{~K}\right): \delta 7.27-$ $7.18(\mathrm{~m}, 3 \mathrm{H}), 7.12-7.07$ (ddd, $J=7.8 \mathrm{~Hz}, 7.6 \mathrm{~Hz}, 1.6 \mathrm{~Hz}$, $1 \mathrm{H}), 3.28-3.20(\mathrm{~m}, 1 \mathrm{H}), 2.82-2.71(\mathrm{~m}, 2 \mathrm{H}), 2.25-2.14(\mathrm{~m}$, 2H), $1.93-1.66(\mathrm{~m}, 4 \mathrm{H}), 1.53-1.43(\mathrm{~m}, 1 \mathrm{H}) ;{ }^{13} \mathrm{C} \mathrm{NMR}$ $\left(100.64 \mathrm{MHz}, \mathrm{CDCl}_{3}, 298 \mathrm{~K}\right): \delta 140.7,135.5,129.5$, 128.0, 125.9, 124.5, 123.3, 122.8, 69.2, 60.5, 40.4, 38.3, $31.2,28.7,26.0$; HRMS: $[\mathrm{M}]^{+}$, found 313.0912 . $\mathrm{C}_{15} \mathrm{H}_{14} \mathrm{Cl}_{3} \mathrm{~N}$ requires 313.0912. 3: yield: $20 \mathrm{mg}(2 \%$, $0.09 \mathrm{mmol}$ ); all spectroscopic data are in accord with those reported in the literature. ${ }^{20}$

4.1.7. Synthesis of 11 under phase transfer conditions. To a solution of $4(1.85 \mathrm{~g}, 10.0 \mathrm{mmol})$, hexadecyltrimethylammonium bromide $(20.4 \mathrm{mg}, 0.056 \mathrm{mmol})$ and one drop of ethanol in $\mathrm{CHCl}_{3}(21.5 \mathrm{~g}, 180 \mathrm{mmol})$ was added under cooling with ice $50 \%$ aqueous $\mathrm{NaOH}(6.0 \mathrm{~g}, 150 \mathrm{mmol})$. The resulting brown two-phase system was vigorously stirred for $18 \mathrm{~h}$ at room temperature, poured into ice water and extracted with $\mathrm{CH}_{2} \mathrm{Cl}_{2}(3 \times)$. The combined organic layers were washed with water $(2 \times)$, brine $(1 \times)$, dried over $\mathrm{Na}_{2} \mathrm{SO}_{4}$ and concentrated at reduced pressure. The crude product was purified by flash column chromatography (silica gel, cyclohexane/EtOAc 99:1 $\rightarrow$ 98:2) to afford $\mathbf{1 1}$ as a yellow oil, which crystallized upon standing. Yield: $650 \mathrm{mg}(21 \%, 2.08 \mathrm{mmol})$. 
4.1.8. Crystal structure determinations. Intensities were measured on a Nonius TurboCAD4 diffractometer with rotating anode (Mo $\mathrm{K} \alpha, \lambda=0.71073 \AA$ ) at a temperature of $150 \mathrm{~K}$. The structures were solved with the program DIRDIF97 ${ }^{21}$ and refined with the program SHELXL-97 ${ }^{22}$ against $\mathrm{F}^{2}$ of all reflections up to a resolution of $(\sin \vartheta / \lambda)_{\max }=0.65 \AA^{-1}$. Nonhydrogen atoms were refined freely with anisotropic displacement parameters. Hydrogen atoms were refined as rigid groups. The drawing and checking for higher symmetry were performed with the program PLATON. $^{23}$

4.1.8.1. Structure of 10. Full details can be obtained from the Cambridge Crystallographic Data Center (CSD number 605984).

4.1.8.2. Structure of 11. Full details can be obtained from the Cambridge Crystallographic Data Center (CSD number 261574).

4.1.9. Computational details. All calculations were performed with the Spartan 04 suite of programs. ${ }^{16}$ Input structures were generated graphically and pre-optimized using the MMFF molecular force field. The lowest energy conformers were located using the MMFF force field in conjunction with the Monte-Carlo algorithm. ${ }^{24}$ Care was taken to perform all further calculations on the lowest energy conformers. For the DFT calculations Becke's nonlocal three-parameter exchange functional (B3) ${ }^{25}$ in conjunction with the nonlocal Lee-Yang-Parr correlation functional (LYP) ${ }^{26}$ and Pople's 6-31G* split valence basis set was used. $^{27}$ Geometry optimizations were performed without imposing symmetry constraints. To ensure well-converged results, the keyword CONVERGE was included. Solvation energies and zero-point vibrational energies have not been included.

\section{Acknowledgements}

These investigations were supported by the Council for Chemical Sciences (GCW) with financial aid from the Netherlands Organization for Scientific Research (NWO).

\section{References and notes}

1. For reviews, see: (a) Tsuji, T. Modern Cyclophane Chemistry; Gleiter, R., Hopf, H., Eds.; Wiley-VCH: Weinheim, 2004; pp 8-104; (b) Vögtle, F. Cyclophane Chemistry; Wiley: Chichester, UK, 1993; (c) Bickelhaupt, F.; de Wolf, W. H. Advances in Strain in Organic Chemistry; Halton, B., Ed.; JAI: London, 1993; pp 185-227.

2. Kawai, H.; Suzuki, T.; Ohkita, M.; Tsuji, M. Chem.-Eur. J. 2000, 6, 4177.

3. (a) Parham, W. E.; Davenport, R. W.; Biasotti, J. B. Tetrahedron Lett. 1969, 10, 557; (b) Parham, W. E.; Davenport, R. W.; Biasotti, J. B. J. Org. Chem. 1970, 35, 3755.

4. Dhanak, D.; Reese, C. B. J. Chem. Soc., Perkin Trans. 11987 , 2829.
5. (a) van Straten, J. W.; de Wolf, W. H.; Bickelhaupt, F. Tetrahedron Lett. 1977, 18, 3317; (b) Turkenburg, L. A. M.; Blok, P. M. L.; de Wolf, W. H.; Bickelhaupt, F. Tetrahedron Lett. 1981, 22, 3317.

6. Makosza, M.; Fedorynski, M. Synth. Commun. 1973, 3, 305.

7. All spectroscopic data are also in accordance with those published in the literature: Thummel, R. P.; Hegde, V. J. Org. Chem. 1989, 54, 1720.

8. Grice, P.; Reese, C. B. Tetrahedron Lett. 1979, 27, 2563.

9. Dhanak, D.; Kuroda, K.; Reese, C. B. Tetrahedron Lett. 1987, 28,1827

10. Grice, P.; Reese, C. B. J. Chem. Soc., Chem. Commun. 1980, 424.

11. (a) For a review, see: Hoffmann, R. W. Acc. Chem. Res. 1985 , 18, 248; (b) A silver(I) promoted opening of a highly strained three-membered ring has been reported: Majerski, Z.; Mlinaric-Majerski. J. Org. Chem. 1986, 51, 3219.

12. Please note that the numbering scheme applied for the X-ray structures of $\mathbf{1 0}$ and $\mathbf{1 1}$ differ from those according to the IUPAC nomenclature.

13. van Eis, M. J.; van der Linde, B. S. E.; de Kanter, F. J. J.; de Wolf, W. H.; Bickelhaupt, F. J. Org. Chem. 2000, 65, 4348.

14. (a) Bachowska, B. Monatshefte für Chemie 2002, 133, 1071; (b) Guillier, F.; Nivoliers, F.; Godard, A.; Marsais, F.; Queguiner, G. J. Heterocycl. Chem. 1999, 36, 1157.

15. The structures of $\mathbf{2 b}$ and $\mathbf{1 1}$ were optimized at the B3LYP/6$31 \mathrm{G}^{*}$ level of theory without imposing geometric constraints.

16. All calculations were performed with the program Spartan 04 suit of programs: SPARTAN'04, Wavefunction Inc., 18401 Von Karman Avenue, Suite 370, Irvine, CA 92612, www. wavefun.com.

17. cf. Wijsman, G. W.; Iglesias, G. A.; Beekman, M. C.; de Wolf, W. H.; Bickelhaupt, F.; Kooijman, H.; Spek, A. L. J. Org. Chem. 2001, 66, 1216.

18. For references about the concept of olefinic strain (OS), see: Maier, W. F.; Von Ragué Schleyer, P. J. Am. Chem. Soc. 1981, 103, 1891; Warner, P. M.; Peacock, S. J. Comput. Chem. 1982, 3, 417.

19. According to a classification by Maier and Schleyer only those anti-Bredt compounds with an OS-value $<17 \mathrm{kcal} / \mathrm{mol}$ are isolable at room temperature, see Ref. 17.

20. Hu, M.; Wu, L.; Hsiao, G.; Yen, M. J. Med. Chem. 2002, 45, 2277.

21. Beurskens, P. T.; Admiraal, G.; Beurskens, G.; Bosman, W. P.; Garcia-Granda, S.; Gould, R. O.; Smits, J. M. M.; Smykalla, C. The DIRDIF Program System. In Technical Report of the Crystallographic Laboratory; University of Nijmegen: Nijmegen, The Netherlands, 1996.

22. Sheldrick, G. M. SHELXL-97, Program for Crystal Structure Refinement; University of Göttingen: Göttingen, Germany, 1997.

23. (a) Spek, A. L. J. Appl. Crystallogr. 2003, 36, 7; (b) Spek, A. L. PLATON. A Multipurpose Crystallographic Tool; Utrecht University: Utrecht, The Netherlands, 1998.

24. The Monte Carlo method implemented in Spartan 04 suit of programs has been used. For the original Monte Carlo paper, see: Metropolis, N.; Rosenbluth, A. W.; Rosenbluth, M. N.; Teller, A. H.; Teller, E. J. Chem. Phys. 1953, 21, 1087.

25. Becke, A. D. J. Chem. Phys. 1993, 98, 5648.

26. Lee, C.; Yang, W.; Parr, G. Phys. Rev. B 1988, 37, 785.

27. Hariharan, P. C.; Pople, J. A. Chem. Phys. Lett. 1972, 16, 217. 